\title{
Agrobacterium-mediated Transformation of Mature Embryo Tissues of Bread Wheat (Triticum aestivum L.) Genotypes
}

\author{
H. Aadel ${ }^{1,2}$, R. Abdelwahd ${ }^{1}$, S.M. Udupa ${ }^{2}$, G. Diria ${ }^{1}$, A. El Mouhtadi ${ }^{1}$, K. Ahansal ${ }^{1}$, \\ F. GABOUN ${ }^{1}$, A. Douira ${ }^{1}$ and D. Iragi ${ }^{1 *}$ \\ ${ }^{1}$ Biotechnology Unit, Institut National de la Recherche Agronomique (INRA), \\ Avenue de la Victoire, B.P. 415, Rabat, Morocco \\ ${ }^{2}$ ICARDA-INRA Cooperative Research Project, International Center for Agricultural Research \\ in the Dry Areas (ICARDA), B.P. 6299, Rabat, Morocco \\ ${ }^{3}$ Laboratory of Botany, Biotechnology and Plant Protection, Faculty of Sciences, Ibn Tofail University, \\ B.P. 133,14000 Kenitra, Morocco
}

(Received 19 January 2017; Accepted 13 June 2017)

\begin{abstract}
Although significant progress has been made on Agrobacterium-mediated wheat transformation, current methodologies using immature embryos as recipient tissues are labor intensive, time consuming and expensive. The use of mature embryos as explants is increasingly being recognized as an optimal method for developing regenerable cell lines during wheat transformation. Therefore, we have developed an Agrobacterium-based transformation protocol using mature embryos while adjusting several factors that influence genetic transformation efficiency. In this study, we focussed on acetosyringone concentrations, genotypes and different types of mature embryos (intact or longitudinally halved-embryos or fragmented into four latitudinal pieces) used as a source of explants for the genetic transformation. A. tumefaciens strain EHA101 harboring the plasmid vector pTF101.1 carrying the barley $H V A 1$ gene and bar-selectable marker gene were used. Mature intact-embryos and longitudinally halved-embryos yielded the highest number of putative transgenic plantlets on the selection medium. However, no plantlets were obtained from latitudinal fragmented mature embryos. 'Amal' and 'Rajae' genotypes regenerated the highest number of putative transgenic plants and $200 \mu \mathrm{M}$ acetosyringone was found to be the optimal concentration for their transformation. A total of 47 transgenic plants were selected with 11 plantlets showing resistance to leaf painting. Molecular analysis revealed that $1 \%$ and $0.66 \%$ of $\mathrm{T}_{0}$ regenerated plantlets were successfully transformed and carried the HVAl gene for the 'Amal' and 'Rajae' genotypes, respectively. Additional analysis shows the transgene is stably inherited in the $\mathrm{T}_{1}$ generation. Based on the results, we conclude that among the influencing factors tested, genotypes, mature embryo explant types and acetosyringone concentration contribute significantly to the success of bread wheat transformation.
\end{abstract}

Keywords: mature embryo, wheat, Agrobacterium tumefaciens, acetosyringone, genetic transformation

Abbreviations: CTAB - Cetyltrimethylammonium bromide; MS medium - Murashige and Skoog; PPT - Phosphinothricin

\footnotetext{
*Corresponding author; E-mail: iraqid@yahoo.fr; Phone: +212661 1646 16 / +212 6601572 42;

Fax: + 212537775530
} 


\section{Introduction}

Wheat (Triticum aestivum L.) is a major global staple food crop that is grown in more than $17 \%$ of the cultivable land and is consumed by almost $40 \%$ of the global population (Peng et al. 2011). Wheat fulfils $21 \%$ of the total calorie and $20 \%$ of the protein requirements of more than 4.5 billion people in developing countries (Braun et al. 2010). Over the years, wheat improvement has attracted considerable attention from plant breeders whose efforts have been primarily focussed on increasing the yield potential, quality characteristics, resistance to biotic stresses, and tolerance to abiotic stresses depending on regional requirements of the crop ( $\mathrm{Ji}$ et al. 2013). Although conventional wheat breeding contributed significantly in wheat improvement, incorporating modern biotechnologies, specifically transgenic approaches could contribute towards more rapid development of improved cultivars.

Genetic transformation is a promising alternative to conventional breeding for the introduction of genes into plants (Xing et al. 2008) such as bar gene (Áy et al. 2012). The first fertile transgenic wheat plants were developed by Vasil et al. (1992), using the microprojectile bombardment transformation method. Subsequently, several improvements were made to the method and used for wheat genetic transformation (Pastori et al. 2001; Pellegrineschi et al. 2002; Áy et al. 2012). Agrobacterium-mediated transformation has been shown to be more effective than biolistic gun because of low copy insertions of T-DNA with minimal rearrangement (Shrawat and Horst 2006). Immature embryos have been the preferred explant for both bread and durum wheat transformation (Jones et al. 2005). Vishnudasan et al. (2005) and Patnaik et al. (2006) tested mature embryos as starter of wheat explants with limited success. Therefore, it appears that gene delivery method based on the use of mature embryos is an excellent system for Agrobacteriummediated transformation as they are not only convenient due to their ease of availability but also for handling large numbers within a reasonable time aiding the recovery of transgenics.

Several key factors, such as genotype, explant, acetosyringone, media composition, length of pre-culture, co-cultivation, selection markers and bacterial strain, have been reported to affect the efficiency of Triticum genus transformation (Wu et al. 2003; Jones et al. 2005). Recently, Ishida et al. (2014) reported that the list of key factors influencing wheat transformation is similar to those studied in other cereals. In this study, we examined the advantages of mature embryos as starter explants for Agrobacterium-mediated transformation of bread wheat to transfer the barley HVAl gene. We also modified several factors to improve the transformation process to enhance the number of transformed plants, such as, genotypes, different types of mature embryo explants and concentrations of acetosyringone. 


\section{Materials and Methods}

\section{Plant materials}

Mature embryos were obtained from four Moroccan genotypes ('Achtar', 'Amal', 'Mehdia' and 'Rajae'). The seeds were procured from the Experimental Research Station of National Institute of Agronomic Research (INRA) at Marchouch, Morocco. These genotypes were previously selected for their high regeneration capacity in vitro (Aadel et al. 2016).

\section{Preparation of bacterial culture for co-inoculation}

The A. tumefaciens strain EHA101 harboring the pTF101.1 plasmid used for transformation has been described in detail by Abdelwahd et al. (2013). The plasmid carries a linked selectable marker/herbicide resistance bar gene (phosphinothricin acetyl transferase gene) and the barley HVA1 gene. Four days prior to the inoculation experiment, Agrobacterium cells harboring $p T F 101.1$ were streaked onto the YEP solid medium supplemented with $100 \mathrm{mg} / \mathrm{L}$ spectinomycin and grown for 3 days at $28^{\circ} \mathrm{C}$. A single colony was subcultured in $5 \mathrm{ml}$ YEP liquid medium at $28^{\circ} \mathrm{C}$ for 2 days in a shaking incubator (set at 250 $\mathrm{rpm}$ ), followed by the addition of $45 \mathrm{ml}$ of fresh YEP liquid medium and a further growth for $5 \mathrm{~h}$. In all the experiments, bacterial cell densities were adjusted to an optical density $\left(\mathrm{OD}_{600 \mathrm{~nm}}=0.7\right)$ using a spectrophotometer immediately before embryo infection.

\section{Preparation of mature embryo explants for co-inoculation with Agrobacterium cells}

Mature wheat seeds were sterilised with $70 \%$ ethanol for $2 \mathrm{~min}$, and then immersed in a $2.4 \%$ bleach (sodium hypochlorite) containing a few drops of Tween-20 for $30 \mathrm{~min}$ at $25{ }^{\circ} \mathrm{C}$. After being rinsed with sterile distilled water three times, the seeds were soaked in sterilized water overnight. The mature embryo tissues were prepared 3 different ways for co-inoculation with Agrobacterium cells supplemented with different concentrations of acetosyringone as follows.

- Intact-mature embryos isolated from the freshly imbibed seeds with a sharp knife and cultured with scutellum side up on the induction medium (Iraqi et al. 2005), modified by (Aadel et al. 2016) for callus formation. The mature embryos were incubated for four days in dark conditions at $25{ }^{\circ} \mathrm{C}$ before co-inoculation with Agrobacterium.

- Mature embryos were removed from the freshly imbibed seeds, cut into two halves longitudinally along the embryonic axis and used directly for co-inoculation with Agrobacterium.

- Mature embryos were gently fragmented into four latitudinal pieces with a sharp blade and cultured on the same induction medium used for intact-mature embryo explants. They were incubated for 7 to 10 days under dark conditions at $25^{\circ} \mathrm{C}$ before coinoculation with Agrobacterium.

The Agrobacterium cells were harvested by centrifugation at $3500 \mathrm{rpm}$ for $10 \mathrm{~min}$ at room temperature. The pellet was gently suspended in the inoculation medium as de- 
scribed in Wang et al. (2009), and supplemented with varying concentrations of acetosyringone $(0,100,200$ and $400 \mu \mathrm{M})$ immediately before inoculation. Control explants were soaked in MS liquid medium without bacteria and acetosyringone. The prepared halves mature embryos or callus tissues derived from the intact-mature embryos and fragmented-embryos were inoculated by immersion in bacterial suspension and incubated for $15 \mathrm{~min}$ at room temperature and the explants were dried with sterile filter paper. The explants were transferred into fresh co-cultivation medium as described by Wang et al. (2009) and incubated at $28^{\circ} \mathrm{C}$ in dark conditions for 2-3 days.

\section{Selection and regeneration}

After co-cultivation, the explants were transferred to selective callus induction medium supplemented with $2 \mathrm{mg} / \mathrm{L}$ picloram, $100 \mathrm{mg} / \mathrm{L}$ casein hydrolysate, $3 \mathrm{mg} / \mathrm{L}$ of phosphinothricin (PPT) and $250 \mathrm{mg} / \mathrm{L}$ of the antibiotic cefotaxime and incubated at $25^{\circ} \mathrm{C}$ in dark conditions for 40 days. Calli that survived to phosphinothricin (PPT) selection were transferred to selective regeneration medium containing $2 \mathrm{mg} / \mathrm{L}$ Kinetin, $0.1 \mathrm{mg} / \mathrm{L}$ geberillic acid and incubated in the presence of light. The surviving regenerated plantlets were transferred for rooting into 1/2 MS-free medium supplemented with $3 \mathrm{mg} / \mathrm{L}$ of phosphinothricin (PPT). Plants showing resistance to PPT were transplanted into soil filled pots and grown in a green-house.

\section{Leaf painting assay}

Herbicide resistance of the putative transgenic wheat plants was determined by painting plant leaves of plants at the fifth leaf stage with basta $(0.3 \%)$, and observations were recorded after 7 days. Plants were scored as susceptible or resistant according to the degree of leaf desiccation after 7 days (Pellegrineschi et al. 2002).

\section{Statistical analysis}

A randomized complete block design (RCBD) was used with 4 genotypes, 4 concentrations of acetosyringone and three types of mature embryo explants conducted in three replicates with 100 explants for each genotype, concentration of acetosyringone and different types of embryo explants. For the analysis of surviving callus and resistant plantlets to selective agent phosphinothricin (PPT), Analysis of Variance (ANOVA) was performed using the General Linear Model (GLM) procedure in SAS (SAS Institute 1985).

\section{DNA analysis of transgenic plants}

Genomic DNA was isolated from the young leaves of putative transgenic plants $T_{0}$ and the positive $\mathrm{T}_{1}$ progeny of $T$. aestivum using a modified CTAB procedure (Udupa et al. 1998). Detection of the bar gene, 35S promoter sequences and barley HVA1 gene in all the putative transgenic plants was performed by PCR amplification using $20 \mu$ solution 
containing 50 ng DNA template, 1x Taq DNA polymerase buffer, $200 \mu \mathrm{M}$ of each dNTP, 0.5 pmol of the respective primers, and 0.6 unit of Taq DNA polymerase (Promega). Primer pairs used to detect the bar gene (402 bp) were 5' GTCTGCACCATCGTCAACC 3' (forward primer) and 5'GAAGTCCAGCTGCCAGAAAC 3' (reverse primer). Primer pairs used to detect the 35S (195 bp) gene were 5' GCACAATCCCACTATCGTTCGC 3' (forward primer) and 5' TCCGTCCACTCCTGCGGTTC 3' (reverse primer). Primer pairs used to assay for the barley HVA1 gene (290 bp) were 5'AGCTAGATCGTGAGACGAAG3' (forward primer) and 5' CCTGCGCCGTCTCGTACGTCTT 3' (reverse primer). DNA amplifications were performed in a thermo-cycler (Master Cycler, Eppendorff, Germany) for both primers (bar and 35S) denaturation at $94{ }^{\circ} \mathrm{C}$ for $4 \mathrm{~min}$, followed by 30 cycles of $1 \mathrm{~min}$ at $94{ }^{\circ} \mathrm{C}, 1 \mathrm{~min}$ at $58^{\circ} \mathrm{C}, 2 \mathrm{~min}$ at $72{ }^{\circ} \mathrm{C}$, and a final $10 \mathrm{~min}$ extension at $72{ }^{\circ} \mathrm{C}$. The PCR program for primers for the barley $H V A 1$ was set at $94{ }^{\circ} \mathrm{C}$ for 3 min for one cycle; the following 35 cycles of $30 \mathrm{~s}$ at $94{ }^{\circ} \mathrm{C}, 30 \mathrm{~s}$ at $55.5^{\circ} \mathrm{C}$, and $45 \mathrm{~s}$ at $72{ }^{\circ} \mathrm{C}$; one cycle at $72{ }^{\circ} \mathrm{C}$ for $10 \mathrm{~min}$; and the final cycle at $4{ }^{\circ} \mathrm{C}$. The reaction mixture was loaded directly onto a $1.2 \%(\mathrm{w} / \mathrm{v})$ agarose gel and $8 \%(\mathrm{w} / \mathrm{v})$ polyacrylamide gel, stained with ethidium bromide, and visualized with UV light (306 nm). The amplified transgene product size was compared with the positive control and the plasmid.

\section{Results}

Effect of mature embryo explants types, genotypes and acetosyringone concentrations on transformation efficiency

This study focussed on determining the role of three factors that may affect the transformation efficiency using three mature embryo explant types (intact or longitudinally halved-embryos or fragmented into four latitudinal pieces), four Moroccan genotypes and four concentrations of acetosyringone. A total of 14,400 embryos were transformed using the Agrobacterium-mediated transformation method (Table S1*). The frequencies of resistant calli were highest using intact-mature embryo (ranged $=4.33$ to $9.26 \%$ ), followed by longitudinally halved-embryos, which varied from $3.20 \%$ to $8.8 \%$. Our observations indicate that the 'Amal' genotype was more sensitive to Agrobacterium infection using intact-mature embryo (range $=7.66$ to $9.26 \%$ ). Furthermore, longitudinally halved-embryos could be used for the 'Rajae' genotype and proved to be a good acceptors for Agrobacterium infection (ranged $=8.13$ to $8.80 \%$ ) (Table S1). The addition of $200 \mu \mathrm{M}$ acetosyringone to Agrobacterium culture significantly improved callus resistant frequencies (range $=8.80 \%$ to $9.26 \%$ ) for both explant types with the 'Rajae' and 'Amal' genotypes, respectively.

\section{Development and identification of $T_{0}$ transgenic plants}

The resistant plantlets regenerated after 3 to 4 days post incubation in the selective regeneration medium (Fig. 1e). The frequencies of resistant plantlets for the four genotypes

\footnotetext{
*Further details about the Electronic Supplementary Material (ESM) can be found at the end of the article.
} 


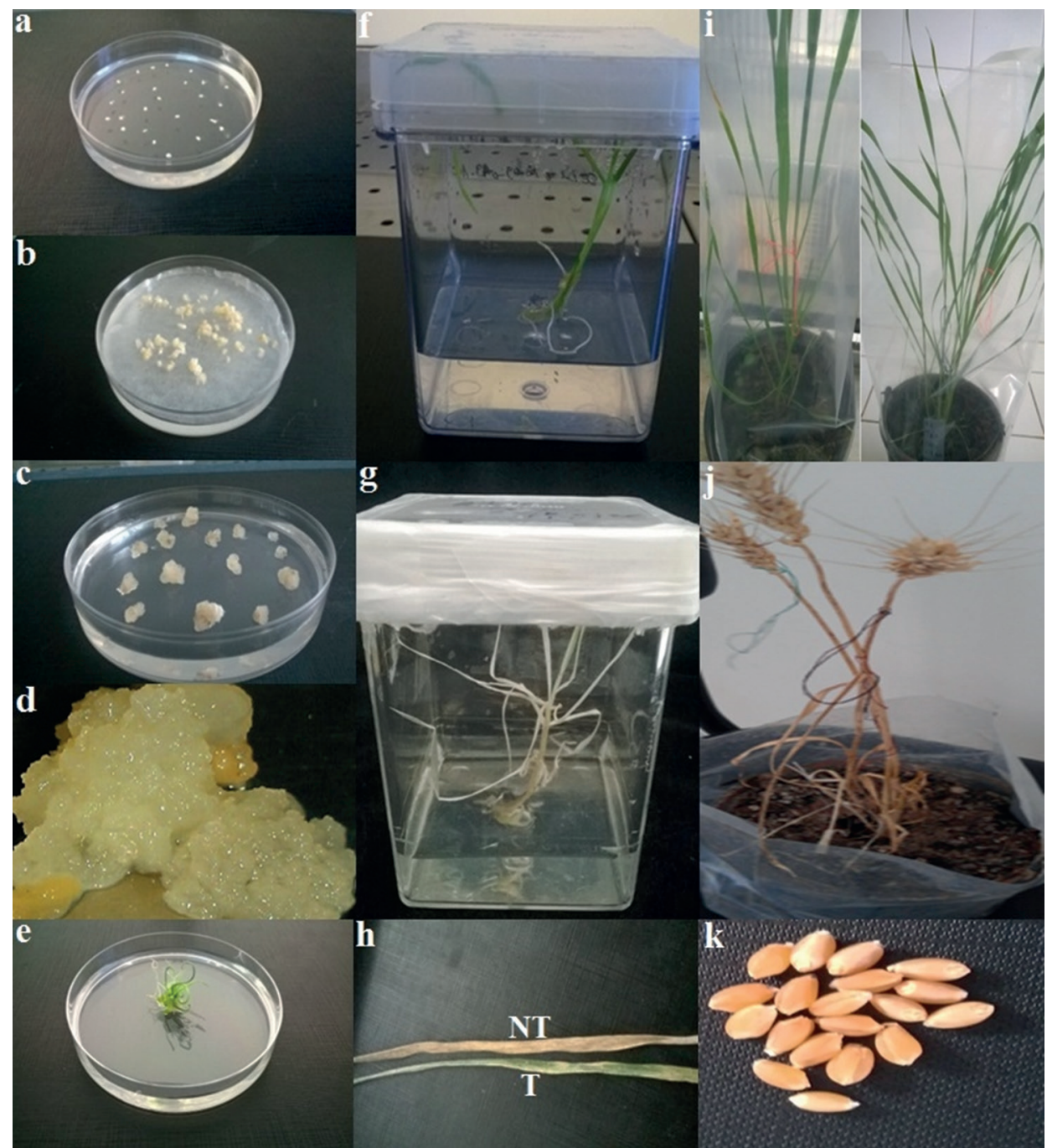

Figure 1. Different phases of transgenic plant development derived from the bread wheat genotypes 'Amal' and 'Rajae' of mature embryos after co-cultivation with Agrobacterium tumefaciens. (a) intact-mature embryo derived from genotype 'Amal', (b) co-cultivation of the longitudinally halved-mature embryos with Agrobacterium derived from genotype 'Rajae', (c) PPT resistant calli derived from intact-mature embryo with genotype 'Amal' after 40 days of culture on selection medium, (d) survivor embryogenic calli on selection medium from genotype 'Amal' with intact-mature embryo, (e) regeneration of putative transgenic plantlet derived from genotype 'Amal' with intact-mature embryo, (f) resistant plantlet after selection with $3 \mathrm{mg} / \mathrm{l}$ of PPT on rooting medium from genotype 'Amal' with intact-mature embryo, (g) untransformed plantlets, (h) results of (PPT) leaf paint assay on $\mathrm{T}_{0}$ transgenic plants of genotype 'Rajae' derived from the longitudinally halved-mature embryo, negative control (NT) and transformant (T) 7 days after Basta panting (0.3\%), (i) acclimation of putative transformed plants, (j) transgenic $\mathrm{T}_{0}$ plant morphologically normal set seeds in a growth greenhouse, $(\mathrm{k})$ morphologically normal transformed mature seeds derived from the wheat genotype 'Amal' with intact-mature embryo 
using intact-mature embryo varied from 0 to $6.93 \%$ (Table S1). For the longitudinally halved-mature embryos, the frequencies of the resistant plantlets were varied from 0.53 to $11.62 \%$; the 'Achtar' genotype did not regenerate any plant using longitudinally halved-mature embryos. Moreover, no plantlets were obtained from the 'Rajae' genotype using intact-mature embryo (Table S1). No plantlet regeneration was observed in recipient tissues prepared from fragmented-mature embryos (4 pieces) with the four tested genotypes (data not shown). The control medium, without acetosyringone, resulted in significantly low level of resistant plantlets using intact-mature embryos and longitudinally halved-mature embryo (0.46 to $1.33 \%$; Table S1). On the other hand, highest level of resistant plantlets were obtained using $200 \mu \mathrm{M}$ of acetosyringone concentration in both the wheat genotypes of 'Rajae' with the longitudinally halved-mature embryo $(11.62 \%)$; and the 'Amal' genotype with an intact-mature embryos (6.93\%; Table S1).

A total of 47 PPT-resistant plantlets were finally regenerated from the resistant calli, 28 plantlets were derived from intact-mature embryos. Nineteen plantlets derived from the longitudinally halved-mature embryos were transplanted into the soil in the greenhouse for acclimatization (Fig. 1i). The upper surfaces of leaflets were painted with Basta (PPT herbicide 0.3\%). After 7 days, we demonstrated the expression of the PPT herbicide-resistance bar gene. Among the 47 plants, 11 painted plants remained green, while the untransformed controls showed necrosis and yellowed and died (Fig. 1h). The PCR experiments (Figs 2, 3) amplified the expected sizes for the bar gene (402 bp), 35S gene promoter (195 bp) and the HVAl gene (290 bp). Three $\mathrm{T}_{0}$ plants regenerated from the genotype 'Amal' with intact-mature embryo were positive, and two $\mathrm{T}_{0}$ plants regenerated from the genotype 'Rajae' with the longitudinally halved-mature embryo with $200 \mu \mathrm{M}$ of acetosyringone were positive and carried the desired the HVAl gene. The transformation efficiency was calculated as the number of transgenic plants obtained plants surviving PPT-selection and PCR-positive for the bar gene, 35S, and HVAl devided by the total number of mature seeds used to prepare the recipient tissues $\times 100$ (Pastori et al. 2001; Pellegrineschi et al. 2002) (Table S1). Based on the PCR results, the transformation efficiency of $\mathrm{T}_{0}$ plants for the two genotypes varied from $1 \%$ with 'Amal' from intact-mature embryo to $0.66 \%$ with the genotype 'Rajae' from the longitudinally halved-mature embryo with the same concentration of acetosyringone $200 \mu \mathrm{M}$.

$35 S$

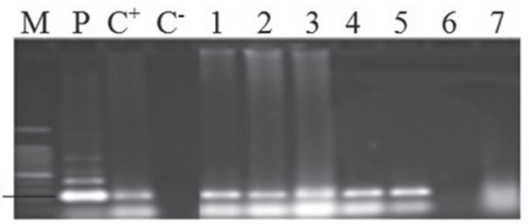

bar

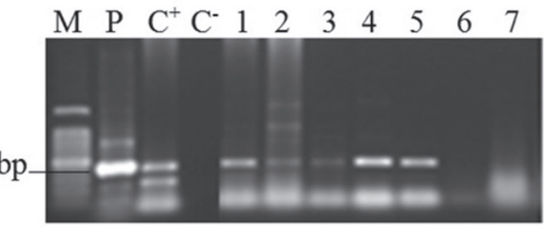

Figure 2. Amplification products obtained from a PCR of genomic DNA of $\mathrm{T}_{0}$ transgenic bread wheat plants with $35 \mathrm{~S}$ and bar gene specific primers which successfully amplified the expected $195 \mathrm{bp}$ and $402 \mathrm{bp}$ gene fragment. M: Marker $100 \mathrm{bp}, \mathrm{P}$ : plasmid (pTF101.1), $\mathrm{C}^{+}$: positive control, $\mathrm{C}^{-}$: negative control (water), 1-2-3: transformed plants from intact-mature embryo of genotype 'Amal', 4-5: transformed plants from the longitudinally halved-mature embryo from genotype 'Rajae', 6-7: negative control of genotypes 'Amal' and 'Rajae' 


\section{HVA1}

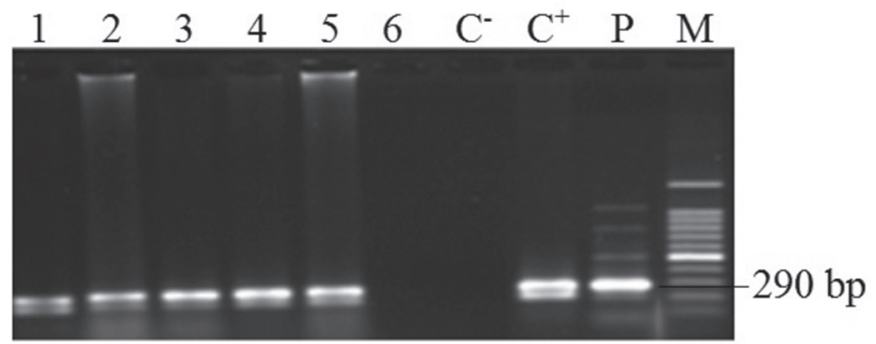

Figure 3. Molecular confirmation of genetic transformation of $\mathrm{T}_{0}$ transgenic genotypes of 'Amal' and 'Rajae' using target primer HVA1. 1-2-3: genomic DNA from leaf tissues of $\mathrm{T}_{0}$ transgenic plants of genotype 'Amal' derived from intact-mature embryos, 4-5: transgenic plant from genotype 'Rajae' derived from longitudinally halved-mature embryo, 6: negative control of genotype 'Amal', $\mathrm{C}^{-}$: negative control (water), $\mathrm{C}^{+}$: positive control, P: plasmid ( $p$ TF101.1), M: Marker100 bp

\section{Analysis of progeny $T_{1}$ plants}

The $\mathrm{T}_{0}$ plants that showed positive results with PCR analysis were germinated in Petri dishes containing absorbent paper pre-wetted with $1000 \mu \mathrm{l}$ sterile water at room temperature. They were then planted in pots in a greenhouse to produce $T_{1}$ generation plants of bread wheat. PCR reactions were used to assess the inheritance of the HVA1, 35S and bar genes in the $\mathrm{T}_{1}$ generation of bread wheat derived from the genotypes 'Amal' and 'Rajae'. The results of PCR analysis for $H V A 1,35 \mathrm{~S}$ and bar genes using genomic DNA of $\mathrm{T}_{1}$ plants confirmed the inheritance of all three genes in the $T_{1}$ generation (Fig. 4, S1). The $\mathrm{T}_{1}$ progeny appeared to be normal phenotypically and similar in morphology to seed-derived control plants.

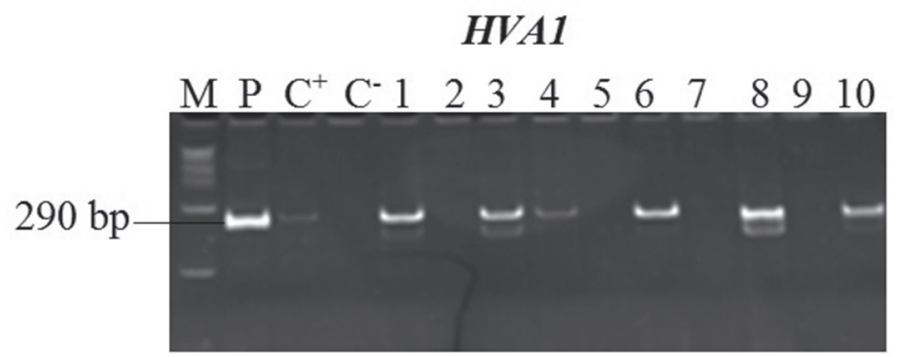

Figure 4. PCR analysis of progeny $\mathrm{T}_{1}$ transgenic bread wheat plants using target primer HVA1. M: Marker 50 bp, P: plasmid (pTF101.1), $\mathrm{C}^{+}$: positive control; $\mathrm{C}^{-}$: negative control (water), 1-3-4: genomic DNA from leaf tissues of three $T_{1}$ transgenic plants of genotype 'Amal', 6-8-10: Genomic DNA from leaf tissues of three $T_{1}$ transgenic plants of genotype 'Rajae', 2-5: genomic DNA from non-transgenic plant as a negative control from genotypes 'Amal' and 'Rajae', 7-9: non transformed plants of genotypes 'Amal' and 'Rajae' 


\section{Discussion}

Advances in wheat genetic transformation are slow as compared to those in rice and maize, partially due to the low efficiency of plant regeneration in wheat tissue culture (Shrawat and Horst 2006). In this study, we have addressed one problem in wheat genetic engineering, which is the low efficiency of plant regeneration in wheat tissue culture transformed by Agrobacterium. Several studies have been conducted on optimizing conditions for improved Agrobacterium-mediated genetic transformation in this major crop (Patnaik et al. 2006), but the transformation efficiency has remained low even when model cultivars were used (Cheng et al. 1997).

In this study, we developed an Agrobacterium based wheat genetic transformation system using the calli derived from intact-mature embryos and longitudinally halvedmature embryos as recipient tissues. The significant difference observed in transformation efficiency (Table S1) reflects the effect of genotype and types of embryo explants. Similar results have been reported by Wang et al. (2009) for the effect of embryo explant types on the transformation efficiency.

In this study, the mature embryos with different types of embryo explants and the callus derived from them showed various levels of sensitivity after being infected with Agrobacterium supplemented with different concentrations of acetosyringone (Table $\mathrm{S} 1$ ). Based on the callus survival rate and the recovery of plants, we deduce that the callus derived from intact-mature embryos were higher than the longitudinally halved-mature embryo and were generally more suitable recipient tissues for Agrobacterium-mediated T-DNA transfer in wheat. Furthermore, no surviving calli and no regenerated plants were observed for the fragmented-mature embryo (data not shown). The concentration of acetosyringone in the inoculation medium plays an important role in Agrobacteriummediated wheat transformation and should be optimized for each explant type and genotype.

The success of the Agrobacterium-mediated transformation differs greatly at various concentrations of acetosyringone and its interaction with various genotypes and explant embryo types. A maximum resistant plant was found in co-cultivation media containing $200 \mu \mathrm{M}$ acetosyringone for both the bread wheat genotypes, i.e. $11.62 \%$ for the genotype 'Rajae' with longitudinally halved-mature embryo explants and $6.93 \%$ for 'Amal' with intact-mature embryo explants (Table S1). The need for acetosyringone has been previously reported for rice; barley and wheat explant types (He et al. 2010). According to the PCR data, the transformation efficiencies were $0.66 \%$ for the genotype 'Rajae' with longitudinally halved-mature embryo and 1\% for the genotype 'Amal' with intact-mature embryos (Table S1). The transgenic wheat plants were derived by using intact-mature embryos from the genotype 'Amal' and the longitudinally halved-mature embryo with the genotype 'Rajae'; show a stable and heritable event (Fig. 4, S1). Most of the transformed plants were fertile and morphologically normal similar to those reported by Wang et al. (2009). Our results show a significant improvement compare to those reported for Agrobacterium-mediated transformation using immature embryo (Liu et al. 2011; Ahmadpour et al. 2015). 
In summary, we successfully introduced the barley HVAl gene via Agrobacterium into bread wheat. Further analysis for tolerance to water stress tolerance and salt tolerance in $\mathrm{T}_{2}$ and subsequent generations will be performed. In addition, we were able to highlight some key points involved in the successful transformation of wheat by Agrobacterium tumefunciens. We showed that transformation efficiency depended mainly on the genotype, type of embryo explants used and the concentration of acetosyringone. However, further optimization of these factors may eventually lead to the development of a robust and more efficient Agrobacterium transformation protocol using mature embryos.

\section{References}

Aadel, H., Ahansal, K., Udupa, S.M., Gaboun, F., Abdelwahd, R., Douira, A., Iraqi, D. 2016. Effect of genotypes and culture media on embryogenic callus induction and plantlet regeneration from mature and immature bread wheat embryos. Rom. Agric. Res. 33:61-69.

Abdelwahd, R., Gan, Q., Udupa, S.M., Diria, G., Mentag, R., Ibriz, M., Iraqi, D. 2013. Cloning the construct HVA1 into a binary vector by Gatway multisite system and genetic transformation of faba bean (Vicia faba L.) with HVA1 gene for improving drought tolerance. Al Awamia Moroccan J. Agric. Res. 127:4-20. (in French)

Ahmadpour, R., Zare, N., Asghari-Zakaria, R., Sheikhzadeh, P. 2015. Enhancement of Agrobacteriummediated transformation efficiency in immature embryo of Triticum aestivum, cv. Arya. Iran Agric. Res. 4:45-53

Áy, Z., Mihály, R., Cserháti, M., Kótai, É., Pauk, J. 2012. The effect of high concentrations of glufosinate ammonium on the yield components of transgenic spring wheat (Triticum aestivum L.) constitutively expressing the bar gene. Sci. World J. 1-9 pp. ID 657945, doi:10.1100/2012/657945

Braun, H.G., Atlin, J., Payne, T. 2010. Multi-location testing as a tool to identify plant response to global climate change. In: Reynolds, M.P. (ed.), Climate Change and Crop Production. CABI Climate Change Series. CABI. Wallingford, IA, USA. pp. 115-138.

Cheng, M., Fry, J.E., Pang, S., Zhou, H., Hironaka, C.M., Duncan, D.R., Conner, T.W., Wan, Y. 1997. Genetic transformation of wheat mediated by Agrobacterium tumefaciens. Plant Physiol. 115:971-980.

He, Y., Jones, H.D., Chen, S., Chen, X.M., Wang, D.W., Li, K.X., Wang, D.S., Xia, L.Q. 2010. Agrobacteriummediated transformation of durum wheat (Triticum turgidum L. var durum cv Stewart) with improved efficiency. J. Exp. Bot. 6:1567-1581.

Iraqi, D., Hakam, N., Labhilili, M. 2005. Transformation génétique des embryons immatures du blé tendre (Triticum aestivum) et du blé dur (Triticum durum) /Genetic transformation of immature embryos of bread wheat (Triticum aestivum) and durum wheat (Triticum durum)/. Al Awamia Moroccan J. Agric. Res. 115:3-16. (in French)

Ishida, Y., Tsunashima, M., Hiei, Y., Komari, T. 2014. Wheat (Triticum aestivum L.) transformation using immature embryos. In: Wang, K. (ed.), Agrobacterium Protocols Methods in Molecular Biology. Springer Science. New York, USA. 1223(1):189-198.

Ji, Q., Xu, X., Wang, K. 2013. Genetic transformation of major cereal crops. Int. J. Dev. Biol. 57:495-508.

Jones, H.D., Angela, D., Wu, H.X. 2005. Review of methodologies and a protocol for the Agrobacteriummediated transformation of wheat. Plant Methods. 1:5.

Liu, X.L., Chen, M.L., Zhao, H.X., Guo, A.G. 2011. Optimization of Agrobacterium-mediated genetic transformation of wheat and transformation of HMW-GS 1Bx14 gene. J. of China Agric. Univ. 16:25-31.

Pastori, G.M., Wilkinson, M.D., Steele, S.H, Sparks, C.A., Jones, H.D., Parry, M.A.J. 2001. Age dependent transformation frequency in elite wheat varieties. J. Exp. Bot. 52:857-863.

Patnaik, D., Vishnudasan, D., Khurana, P. 2006. Agrobacterium-mediated transformation of mature embryos of Triticum aestivum and Triticum durum. Curr. Sci. 91:307-317. 
Pellegrineschi, A., Noguera, L.M., Skovmand, B., Brito, R.M., Velazquez, L., Salgado, M.M., Hernandez, R., Warburton, M., Hoisington, D. 2002. Identification of highly transformable wheat genotypes for mass production of fertile transgenic plants. Genome 45:421-430.

Peng, J., Sun, D., Nevo, E. 2011. Wild emmer wheat, Triticum dicoccoides, occupies a pivotal position in wheat domestication. Aust. J. Crop. Sci. 5:1127-1143.

SAS Institute. 1985. SAS/STAT Guide for Personal Computers, Version 6 edition. SAS Institute. Cary, NC, USA, $378 \mathrm{p}$.

Shrawat, A.K., Horst, L. 2006. Agrobacterium-mediated transformation of cereals: a promising approach crossing barriers. J. Plant. Biotechnol. 4:575-603.

Udupa, S.M., Weigand, F., Saxena M.C., Kahl, G. 1998. Genotyping with RAPD and microsatellite makers resolves pathotype diversity in the ascochyta blight pathogen of chickpea. Theor. Appl. Genet. 97:299-307.

Vasil, V., Castillo, A.M., Fromm, M.E., Vasil, I.K. 1992. Herbicide resistant fertile transgenic wheat plants obtained by microprojectile bombardment of regenerable embryogenic callus. Bio. Technology 10:667674.

Vishnudasan, D., Tripathi, M.N., Rao, U., Khurana, P. 2005. Assessment of nematode resistance in wheat transgenic plants expressing potato proteinase inhibitor (Pin2) gene. Transgenic Res. 14:665-675.

Wang, Y.L., Xu, M.X., Tao, L.L., Wang, D.W., Ye, X.G. 2009. Transgenic wheat plants derived from Agrobacterium-mediated transformation of mature embryo tissues. Cereal Res. Commun. 37:1-12.

Wu, H., Sparks, C., Amoah, B., Jones, H.D. 2003. Factors influencing successful Agrobacterium-mediated genetic transformation of wheat. Plant Cell Rep. 21:659-668.

Xing, Y.J., Ji, Q., Yang, Q., Luo, Y.M., Li, Q., Wang, X. 2008. Studies on Agrobacterium-mediated genetic transformation of embryogenic suspension cultures of sweet potato. Afr. J. Biotechnol. 7:534-540.

\section{Electronic Supplementary Material (ESM)}

Electronic Supplementary Material (ESM) associated with this article can be found at the website of CRC at http://www.akademiai.com/content/120427/

Electronic Supplementary Table S1. Transformation efficiency of bread wheat genotypes using intact-mature embryos and longitudinally halved-mature embryos as explant source with different concentrations of acetosyringone after Agrobacterium infection with strain EHA101 (pTF101.1) and selection on phosphinothricin (PPT) medium

Electronic Supplementary Figure S1. PCR analysis of some progeny of transgenic bread wheat plants. The presence of the $35 S$ and bar gene were proven by electrophoresis of amplified product 195 bp and $402 \mathrm{bp}$ on from plants of $\mathrm{T}_{1}$ genotype of 'Amal' and 'Rajae'. M: Marker $50 \mathrm{bp}, \mathrm{P}$ : plasmid ( $p$ TF101.1), $\mathrm{C}^{+}$: positive control, $\mathrm{C}^{-}$: negative control (water), 1-2-4: Genomic DNA from leaf tissues of three $\mathrm{T}_{1}$ transgenic plants of genotype 'Amal', 5-7-8, Genomic DNA from leaf tissues of three $T_{1}$ transgenic plants of genotype 'Rajae', 3-6: Genomic DNA from non-transgenic plant as a negative control from genotype 'Amal' and 'Rajae' 